\title{
Carbendazim exposure induces developmental, biochemical and behavioural disturbance in zebrafish embryos
}

\author{
Thayres S Andrade ${ }^{1}$, Jorge F Henriques ${ }^{1}$, Ana Rita Almeida ${ }^{1}$, Ana Luísa Machado ${ }^{1}$, \\ Olga Koba ${ }^{2}$, Pham Thai Giang ${ }^{2}$, Amadeu M.V.M. Soares ${ }^{1}$, and Inês Domingues ${ }^{1}$ \\ ${ }^{1}$ Dept. of Biology and CESAM, University of Aveiro, Campus Universitário de \\ Santiago, 3810-193 Aveiro, Portugal. \\ ${ }^{2}$ University of South Bohemia in Ceske Budejovice, Faculty of Fisheries and Protection \\ of Waters, South Bohemian Research Center of Aquaculture and Biodiversity of \\ Hydrocenoses, Zatisi 728/II, Vodnany 389 25, Czech Republic.
}

Corresponding author:

Thayres S Andrade

Telephone: (+351) 961211396

Fax: (+351) 234372587

email: thayres@gmail.com;

\begin{abstract}
Carbendazim is a widely used broad spectrum benzimidazole fungicide; however, its effects to non-target aquatic organisms are poorly studied. The aim of this study was to investigate the toxic effects of carbendazim to zebrafish early life stages at several levels of biological organization, including developmental, biochemical and behavioural levels. The embryo assay was done following the OECD guideline 236 and using a concentration range between 1.1 and $1.8 \mathrm{mg} / \mathrm{L}$. Lethal and developmental endpoints such as hatching, edemas, malformations, heart beat rate, body growth and delays were assessed in a 96 hours exposure. A sub-teratogenic range (from 0.16 to $500 \mu \mathrm{g} / \mathrm{L}$ ) was then used to assess effects at biochemical and behavioural levels. Biochemical markers included cholinesterase (ChE), glutathione-S-transferase (GST), lactate dehydrogenase (LDH) and catalase (CAT) and were assessed at 96 hours. The locomotor behaviour was assessed using an automated video tracking system at 120 hours.
\end{abstract}


Carbendazim (96h-LC $\mathrm{LC}_{50}$ of $\left.1.75 \mathrm{mg} / \mathrm{L}\right)$ elicited several developmental anomalies in

LDH activities were increased at concentrations equal or above $4 \mu \mathrm{g} / \mathrm{L}$. The locomotor assay showed to be extremely sensitive, detecting effects in time that larvae spent swimming at concentrations of $0.16 \mu \mathrm{g} / \mathrm{L}$ and thus, being several orders of magnitude more sensitive that developmental parameters or lethality. These are ecological relevant concentrations and highlight the potential of behavioural endpoints as early warning signs for environmental stress. Further studies should focus on understanding how the behavioural disturbances measured in these types of studies translate into fitness impairment at the adult stage.

Keywords: zebrafish, locomotor response, biomarkers, sublethal, swimming behaviour

\section{Introduction}

Carbendazim (methyl-1-H-benzimidazol-2-yl-carbamate) is one of the most widely used benzimidazole fungicides. It is highly toxic to target organisms, inhibiting the development of a wide variety of fungi even at low doses. It is used in agriculture, horticulture, forest and home gardening and as a preservative in paint, papermaking, textile, leather industry and fruits (Selmanoğlu et al., 2001). Carbendazim is a metabolite of benomyl and it is known to target the tubulin in cells, causing disruption of microtubule assembly and cell division (Davidse, 1986).

Low concentrations of carbendazim ranging from 0.2 to $200 \mu \mathrm{g} / \mathrm{L}$ have already been detected in surface waters near agriculture and forestry areas (Palma et al., 2004; Readman et al., 1997). Moreover, carbendazim has shown to be very persistent in the water with a half-life of 6 to 25 weeks (Cuppen et al., 2000a). Many studies have reported the adverse effects of carbendazim on mammals, mainly on reproductive organs (Farag et al., 2011; Ireland et al., 1979; Lim and Miller, 1997; Nakai et al., 2002; Urani et al., 1995), but unlike mammals, effects on aquatic organisms are poorly studied. The majority of studies available focus on zooplankton and macroinvertebrate communities in which chronic exposures to carbendazim decreased survival, reproduction and feeding rates (Cuppen et al., 2000b; Daam et al., 2010; Ferreira et al., 2008; Ribeiro et al., 2011; Van den Brink et al., 2000). To our knowledge, only two studies report carbendazim effects on fish early life stages. Ludwikowska et al. (2013) 
showed that carbendazim affects the survival and hatching success of Prussian carp embryonic exposure to carbendazim led to significant changes in the expression of genes related to apoptosis, immunotoxicity and endocrine disruption in zebrafish (Danio rerio). In this later study concentrations between 4 and $500 \mu \mathrm{g} / \mathrm{L}$ of carbendazim were tested.

Risk characterization is better achieved by studying chemical effects at several levels of biological organization. Recently, behavioural parameters such as locomotion (whose evaluation have been considered time consuming and lacking objectivity) have been increasingly used due to the development of technology for automated analysis. In the case of zebrafish, locomotion has been used as an endpoint to assess the neurotoxic effects of chemicals in early life stages (Irons et al., 2010; Padilla et al., 2011; Selderslaghs et al., 2010) and the sublethal toxicity of pollutants (Ulhaq et al., 2013). In fact, many contaminants disrupt fish behaviour at concentrations much lower than those causing mortality, eg: Klüver et al. (2015) recorded alteration of behaviour of fish embryos at concentrations 375 -fold lower than the $\mathrm{LC}_{10}$. Thus, behaviour has proven to provide very sensitive measures of stress exposure; furthermore it has high ecological relevance as effects can be translated long term health and survival of populations (Scott and Sloman, 2004; Tierney, 2011).

Recently, the approval of the OECD test guideline 236 (fish embryo toxicity test) has consolidated the zebrafish embryo test as a true alternative for the acute fish toxicity test with adults (Braunbeck et al., 2014) in the European Union. This test has been increasingly used to assess the toxicity of chemicals and waste waters as reviewed by Scholz et al. $(2008,2013)$. The low volume of test solutions needed (tests are deployed in 24 or 96-wells microplates) and the rapid development and transparency of embryos that allow the monitoring of the entire organogenesis are among the advantages of this test. Zebrafish embryos also comprise an excellent model for determining the effects of chemicals at biochemical level (Oliveira et al., 2009).

Thus, based on the hypothesis that carbendazim could have serious adverse effects in fish early life stages, the aim of this work was to assess the toxic effects of carbendazim in zebrafish embryos at several organizational levels, namely:

i) lethality,

ii) developmental (including embryo development delays and malformations), 
iv) biochemical (including the measurement of the enzymes ChE-cholinesterase, GSTglutathione S-transferase, LDH-lactate dehydrogenase and CAT-catalase) and

v) behavioural (by measuring locomotion of zebrafish eleutheroembryos expressed by distance moved and time spent moving)

The parameters selected to be evaluated at biochemical levels include not only parameters directly related to neurobehavioral action as it is the case of ChE but also enzymes representative of different metabolic pathways such as GST (involved in the phase II of the detoxification process), LDH (involved in the anaerobic way of energy production) and CAT (involved in the antioxidant defence).

Is this way an integrated analysis of carbendazim can be done contributing to understand the mechanisms of toxicity of this compound.

\section{Materials and Methods}

\subsection{Zebrafish maintenance and embryo collection}

All the embryos used in the present study were provided by the zebrafish facility established at the Department of Biology, University of Aveiro (Portugal). Adults were maintained in carbon-filtered water, complemented with $0.34 \mathrm{mg} / \mathrm{L}$ salt ("Instant Ocean Synthetic Sea Salt", Spectrum Brands, USA) and automatically adjusted for $\mathrm{pH}$ and conductivity. Water temperature was kept at $26.0 \pm 1{ }^{\circ} \mathrm{C}$, conductivity at $750 \pm 50 \mu \mathrm{S}$, $\mathrm{pH}$ at $7.5 \pm 0.5$ and dissolved oxygen equal or above $95 \%$ saturation. A 16:8 h (light:dark) photoperiod cycle was maintained. This reconstituted water was used in the preparation of test solutions of all assays performed. The above mentioned temperature and photoperiod conditions were constant in all assays. Zebrafish eggs were obtained by crossbreeding of individuals in aquaria; after $30 \mathrm{~min}$ of natural mating, eggs were rinsed in water and checked under a stereomicroscope (Stereoscopic Zoom Microscope -SMZ 1500, Nikon Corporation); those unfertilized, with cleavage irregularities, injuries or other kind of malformations were discarded.

\subsection{Test Chemicals and Preparation of Test Solutions}

Carbendazim (Methyl 2-benzimidazolecarbamate, 97\% purity) was purchased from Sigma-Aldrich. Carbendazim solutions were carefully prepared by dissolving carbendazim on the zebrafish water system. Ten millilitres of each tested concentration was sampled at the beginning and at the end of the assay and preserved at $-20{ }^{\circ} \mathrm{C}$ for further chemical analysis. The chemical analysis aimed to assess the degradation of carbendazim in the test solutions and was performed at Laboratory of Environmental 
Chemistry and Biochemistry, University of South Bohemia in České Budějovice, Czech Republic.

\subsection{Embryo assay}

The assay was based on the OECD testing guideline 236 on Fish Embryo Acute Toxicity (FET) Test (OECD, 2013). A range finding test was conducted in which no mortality was observed at concentrations equal or below $1 \mathrm{mg} / \mathrm{L}$ of carbendazim and $100 \%$ of mortality was recorded at concentrations equal or higher than $2 \mathrm{mg} / \mathrm{L}$ (data not shown). Thus, based on these results the following carbendazim concentrations were used: $1.1,1.19,1.3,1.41,1.53,1.66$ and $1.8 \mathrm{mg} / \mathrm{L}$. Ten embryos (approximately $3 \mathrm{hpf}$ ) were used per replicate (3 replicates were used per treatment) and distributed individually in 24-wells microplates ( $2 \mathrm{ml}$ of test solution per well). As carbendazim showed to be stable throughout the period of the test, the medium was not renewed. Test run for 96 h. Embryos were daily observed under a stereomicroscope (Stereoscopic Zoom Microscope - SMZ 1500, Nikon Corporation, Japan) and the following parameters were evaluated: survival, somite formation, incidence of pericardial edema, heart beat, malformations (general, spinal, tail and head), hatching, body length (total length: snout to tail tip), yolk sac length and developmental delay. The heartbeat (beats/15s) was measured by counting heart beats under a stereomicroscope in 3 randomly selected embryos of each replicate ( $n=9$ per concentration) at $48 \mathrm{~h}$. The body and yolk sac length was measured using digital images of the embryos with the software NIS Elements D (Nikon Corporation, Tokyo, Japan). Development delay was obtained by matching the developmental stage of a given embryo with the developmental stages defined by Kimmel et al., (1995).

A sublethal range of carbendazim concentrations $(0.16,0.8,4,20,100$ and $500 \mu \mathrm{g} / \mathrm{L})$ was used to set up the test for biochemical determinations and locomotory analysis. This test was deployed in the same conditions as the above described test. At 96 hours of exposure, 10 clusters of eight larvae per treatment were snap-frozen in microtubes containing $0.8 \mathrm{ml}$ of $\mathrm{K}$-phosphate buffer $(0.1 \mathrm{M}, \mathrm{pH} 7.4)$ and stored at $-80^{\circ} \mathrm{C}$ for further enzymatic analysis (see section 2.4). For locomotory assay, larvae were exposed until $120 \mathrm{~h}$ and then transferred to 96 well plates and analysed using the track system Zebrabox (Viewpoint, Lyon, France) (see section 2.5).

\subsection{Biomarkers determinations}


Enzymatic determinations were made spectrophotometrically (Thermo Scientific analyses, samples were defrosted on ice, homogenised (KIKA Labortechnik U2005 Control) and centrifuged $\left(4{ }^{\circ} \mathrm{C}, 10000 \mathrm{~g}, 20 \mathrm{~min}\right)$ in order to isolate the postmitochondrial supernatant (PMS) posteriorly used as enzyme extract for activity determinations.

The methods for the determination of ChE, GST, LDH and CAT activity are described in Domingues et al. (2010). Briefly, ChE activity was determined at $414 \mathrm{~nm}$ according to the method of Ellman et al. (1961); GST activity was performed at $340 \mathrm{~nm}$ as described by Habig and Jakoby (1981); the LDH activity was measured at $340 \mathrm{~nm}$, following the methodology described by Vassault (1983) and the CAT activity was measured at $240 \mathrm{~nm}$ as described by Clairborne (1985).

Protein quantification in samples was performed in quadruplicate according to the Bradford method (Bradford, 1976), at $595 \mathrm{~nm}$, using $\mathrm{\gamma}^{-}$globulin to determine standard curve. Enzymatic activity units were expressed in nanomoles of substrate hydrolysed per minute per mg of protein.

\subsection{Analysis of locomotor response}

Zebrafish larvae were used to assess the effects of carbendazim on locomotory activity. At $120 \mathrm{hpf} 12$ larvae per treatment (in triplicate) were transferred from the exposure dishes to 96 well plates (one per well). Dead larvae or larvae exhibiting physical abnormalities were not included in the locomotor analyses. Movement was tracked using the Zebrabox (Viewpoint, Lyon, France) tracking system using a 25 frame per second infrared camera over a period of $50 \mathrm{~min}$. The temperature was maintained stable at $26 \pm 1{ }^{\circ} \mathrm{C}$. Movement was stimulated by alternating light and dark periods according to what was previously described in Irons et al. (2010). Briefly, the test started by an acclimation period where embryos were placed for $10 \mathrm{~min}$ in the light, followed by a cycle of four alternating periods: 10 min dark; 10 min light; 10 min dark and 10 min light. Typically zebrafish larvae show less locomotion during light periods and more during dark. Data outputs were obtained at each 2 minutes and the following parameters were calculated: total distance moved, relative small and large distance moved (a movement was considered "small" when individuals moved less than 0.5 $\mathrm{mm} / \mathrm{sec}$ ) and relative swimming time. The total distance consists of the total swimming distance of the larvae during each measurement period. The relative small distance (\%) 
is the ratio between small distance moved and total distance moved in each $10 \mathrm{~min}$ period. The relative large distance $(\%)$ is the ratio between large distance and the total distance moved in each measurement period. Finally, the relative swimming time refers to the time embryos spend moving (swimming) relative to the total measurement period. A threshold of 30 was used for background correction.

\subsection{Determination of carbendazim in water using liquid chromatography-tandem mass} spectrometry

\subsubsection{Chemicals}

Liquid chromatography-mass spectrometry (LC-MS) grade methanol and acetonitrile ( $\mathrm{Li}$ Chrosolv Hypergrade) were obtained from Merck (Darmstadt, Germany). Formic acid used to acidify the mobile phases was purchased from Labicom (Olomouc, Czech Republic). Ultra-pure water was produced using an Aqua-MAX-Ultra System (Younglin, Kyounggi-do, Korea). All compounds used were analytical standards or of high purity (>98\%). ${ }^{13} \mathrm{C}_{6}$ labeled trimethoprim was purchased from Cambridge Isotope Inc. (Andover, MA, USA) and it was used as internal standard because it has quite similar retention time as carbendazim (elution time is $4.98 \mathrm{~min}$ for carbendazim and $5.35 \mathrm{~min}$ for labeled trimethoprim).

Stock solutions of carbendazim and labeled trimethoprim were prepared in methanol at a concentration of $1 \mathrm{mg} / \mathrm{ml}$ and stored at $-20^{\circ} \mathrm{C}$. A spiking mixture was prepared for each compound by diluting stocks in methanol to concentration of $1 \mu \mathrm{g} / \mathrm{mL}$ and stored at $-20^{\circ} \mathrm{C}$.

\subsection{2. $L C-M S / M S$ analysis}

A triple stage quadrupole MS/MS TSQ Quantum Ultra mass spectrometer (Thermo Fisher Scientific, San Jose, CA, USA) coupled with an Accela 1250 LC pump (Thermo Fisher Scientific) and an HTS XT-CTC autosampler (CTC Analytics AG, Zwingen, Switzerland) was used for analysis of carbendazim in water samples. Thawed water samples were filtered through a syringe filter $(0.45 \mu \mathrm{m}$, regenerated cellulose, Labicom, Olomouc, Czech Republic), after that $10 \mathrm{ng}$ of internal standard was added to $1 \mathrm{~mL}$ of sample.

An analytical Cogent Bidentate C18 column (50 mm x $2.1 \mathrm{~mm}$ ID x $4 \mu \mathrm{m}$ particles, Thermo Fisher Scientific) was used for chromatographic separation of the target analytes. Ionization of targeted compounds was carried out with heated electrospray ionization (HESI). The spray voltage was $3.5 \mathrm{kV}$. Nitrogen (purity > $99.99 \%$ ) was used 
as the sheath gas (40 arbitrary units), auxiliary gas (10 arbitrary units) and collision gas. separation of targeted analytes was provided with acidified acetonitrile/ultrapure water gradient presented in the Table S1 (Supplementary data).

Two product ions from carbendazim $192 \rightarrow 159$, used for quantification, and $192 \rightarrow 131$, used for qualification, were monitored in positive ion mode during analysis.

Developed method was validated in the range of tested concentrations. The method showed good linearity in the concentration range from 0.001 to $1 \mathrm{mg} / \mathrm{L}$ of carbendazim with $\mathrm{R}^{2}=0.998$.

Recovery of carbendazim from aquaria water was evaluated by spiking water samples with the target compound. Recovery value for carbendazim was $100 \%$. The average carbendazim limit of quantification (LOQ) was $0.16 \mu \mathrm{g} / \mathrm{L}$ and was calculated as one quarter of the lowest calibration point in the calibration curve where relative standard deviation of average response factor was $<30 \%$.

Matrix-matched standard response was used as factors for correcting the response derived from the calibration curve. Matrix-matched standard was prepared from tested water blank by spiking with both internal standard and native compound at $0.01 \mathrm{mg} / \mathrm{L}$ and $1 \mathrm{mg} / \mathrm{L}$, respectively.

\subsection{Statistical analysis}

Lethal concentration (LCx) and effect concentration (ECx) values were calculated for each endpoint by fitting dose-response curves using the package drc in the software $\mathrm{R}$ (R Core Team, 2014). A one-way analysis of variance (ANOVA) was used to test differences in the locomotor behaviour between the treatments in each interval (light or dark). The acclimation period that was not included in the analysis. In the case datasets failed the normality and homoscedasticity test, an ANOVA on ranks (Kruskall-Wallis) was performed. When significant, differences were further explored with appropriate post hoc test (Dunnet's or Dunn's) to compare each treatment against control. Test statistics and analysis of normality were conducted using the software SigmaPlot V.12.5 (SysStat, San Jose, California, USA). A significance level of 0.05 was used to infer statistically significant results. The relationship between the different treatments/concentrations of carbendazin and the overall behavioural and biochemical endpoints was investigated by a Principal Component Analysis (PCA). Behavioural and biomarkers data were standardized (scaled into 0-1 range), in order to be used in the 
same ordination plot. PCA was performed using CANOCO 4.5 software (Lepš and Šmilauer, 2003).

\section{Results}

\subsection{Stability of carbendazim in the exposure medium}

Chemical analysis of the exposure media showed stable exposure concentrations and within $80-120 \%$ of the nominal concentrations in what refers the FET test $(1.1-$ $1.8 \mathrm{mg} / \mathrm{L})$. However, analysis of the exposure media of the sublethal range of concentrations $(0.16-500 \mu \mathrm{g} / \mathrm{L})$ revealed some inconsistencies (Table S2, Supplementary data) probably because the tested concentrations were very close to the limit of quantification.

\subsection{Effects on embryos development}

The calculated $\mathrm{LC}_{50}$ and $\mathrm{EC}_{50}$ values for zebrafish embryos exposed to carbendazim are presented in Table 1. Carbendazim showed to be moderately toxic to zebrafish embryos, with a $96 \mathrm{~h}-\mathrm{LC}_{50}$ of $1.76 \mathrm{mg} / \mathrm{L}$ (Fig S1and Table 1).

Carbendazim also affected the development of embryos by triggering a series of developmental anomalies including the incidence of edema, spine, head and tail deformities and also reducing heart rate, body length and the rate of consumption of the yolk sac. Although carbendazim did not cause significant mortality at $24 \mathrm{hpf}$, embryos exposed to concentrations above $1.3 \mathrm{mg} / \mathrm{L}$ exhibited developmental anomalies such as tail and spine deformities presenting an $\mathrm{EC}_{50}$ of $1.48 \mathrm{mg} / \mathrm{L}$ (Table 1). At $48 \mathrm{hpf}$ an increment in the frequency of edemas and spine curvature was observed with a $\mathrm{EC}_{50}$ of $1.26 \mathrm{mg} / \mathrm{L}$ and $1.53 \mathrm{mg} / \mathrm{L}$ respectively (Table 1, Fig $\mathrm{S} 2 \mathrm{a}$ and b). Moreover, carbendazim induced a significant reduction in heart beat rate affecting even embryos exposed to the lowest concentration of $1 \mathrm{mg} / \mathrm{L}$. Embryos exposed to control exhibited a heart beat around 180 beats/ min while embryos exposed to the highest concentrations presented a heart beat rate around 100 beats/ min (Table 1, Fig S2 c).

At $72 \mathrm{hpf}$, along with an increase in malformations, carbendazim reduced hatching rate in exposed embryos with a $\mathrm{EC}_{50}$ of $1.57 \mathrm{mg} / \mathrm{L}$ (Table 1, Fig S3 a). Concerning morphological effects, the most important anomalies found were head and eye malformation, spine curvature and edemas (mainly pericardial edemas) as can be observed in Fig 1 and Fig S3 (see Table 1 for $\mathrm{EC}_{50}$ values).

These effects persisted until $96 \mathrm{hpf}$ in several endpoints including hatching, deformities in the head, tail and spine and pericardial edema (see Fig S4 for dose 
response curves, Fig 1G-I for visual evidence and Table 1 for $\mathrm{EC}_{50}$ values). In addition,

carbendazim significantly affected body and yolk sac length of embryos as can be observed in Table 1 and Fig. S4 e. The body length of embryos decreased as carbendazim concentrations increased and effects were detected even at the lowest concentration tested. In contrast a significant increase was observed in yolk sac length in concentrations above $1.30 \mathrm{mg} / \mathrm{L}$ which may be related to a delay in the consumption of the yolk.

\subsection{Biomarkers}

The effects of carbendazim on the activities of biomarkers ChE, GST, LDH and $\mathrm{CAT}$, are presented in Figure 2. Exposure to carbendazim significantly induced $\mathrm{ChE}$ $\left(\mathrm{F}_{6,34}=5.18 ; \mathrm{P}=0.001\right)$, GST $\left(\mathrm{F}_{6,28}=10.59 ; \mathrm{P}<0.001\right)$ and $\mathrm{LDH}(\mathrm{H}=20.70 ; \mathrm{P}=0.002)$ activities at concentrations $\geq 4 \mu \mathrm{g} / \mathrm{L}$ when compared to control group (Fig a-c). Regarding CAT activity, although a slightly decrease in activity was observed at concentration below $4 \mu \mathrm{g} / \mathrm{L}$, no statistically significant differences were observed $\left(F_{6}\right.$, $\left.{ }_{33}=1.36 ; \mathrm{P}=0.268\right)$.

\subsection{Behavioural changes: locomotor response}

Results within the two periods of light and within the two periods of dark tested were very similar and thus, only the results of the first dark and light periods will be here presented (Fig 3). Carbendazim induced changes in the locomotor activity of zebrafish larvae at 120 hpf. Fig. 3 a-b shows the results for total distance moved (mm) in the dark and in the light period. During the dark period, no statistical differences were found on any treatment when compared to control although the One way Anova revealed an effect of carbendazim $(\mathrm{H}=16.49 ; \mathrm{P}=0.011)$. However, during the light period a significant $(\mathrm{F}=2.13 ; \mathrm{P}=0.002)$ decrease in the distance moved was observed at concentrations above $0.8 \mu \mathrm{g} / \mathrm{L}$ (Fig 3 b).

Small and large distances are complementary parameters as can be seen in Fig $3 \mathrm{c}$ and $e$ and $d$ and $\mathrm{f}$. Although an effect was observed for these parameters, they do not present a dose-response pattern. Generally, in the dark periods, organisms exposed to intermediate concentrations of carbendazim presented lower percentages of small distance movements (and higher \% of large distance movements) when compared to control, Fig $3 \mathrm{c}$ and e. In the light period only organisms exposed to the highest concentration presented a differentiated behaviour compared to control, translated by a 
decreased percentage of small distance movements (and increased \% of large distance movement), Fig $3 \mathrm{~d}$ and $\mathrm{f}$.

In relation to the relative swimming time, larvae exposed to carbendazim presented a longer swimming time when compared to control group in both dark $(\mathrm{F}=27.44 ; \mathrm{P}=$ $<0.001)$ and light $(\mathrm{H}=47.30 ; \mathrm{P}=<0.001)$ (Fig $3 \mathrm{~g}-\mathrm{h})$. This effect was concentration dependent and differences could be perceived even at the lowest concentrations tested either for dark or for light periods.

\subsection{PCA}

In the PCA related to the light period (Figure 4-A), the first two ordination axes explained $72.2 \%$ of the total variation. The primary axis represented $55.4 \%$ of the variation and described an increase on the activity of all the measured biomarkers and also swimming time (ST) along with the decrease of total swimming distance (TD). Higher enzymatic activity and longer swimming time are related with higher concentration of carbendazim, while control samples and lower concentrations of the chemical are related with greater swimming distance. The second axis explained a variation of $16.8 \%$ and described a gradient of increasing percentage of long distance swimming but there was no clear pattern between these behaviour parameter and carbendazim concentrations.

The PCA for the dark period (Figure 4-B) presented an overall similar pattern. The first two axes represented $75.0 \%$ of the total observed variation. Primary variation captured $53.1 \%$ of the global variation and described an increase of the enzymatic activity, followed by ST. Again, the increase of these parameters is associated to higher concentrations of carbendazim. Secondary axis, that explains $21.9 \%$ of the total variation, describes an increase in both TD and large distance percentage (LD), but without a clear relationship with carbendazim concentrations.

\section{Discussion}

Carbendazim acts by inhibiting the assembly of tubulin and the formation of microtubules in fungi, and also in mammals (Davidse, 1986; Ireland et al., 1979; Lim and Miller, 1997). Thus, carbendazim effects are prone to be more relevant in very early embryonic life stages where active cell division is ongoing. This may explain why in this work the lethal toxicity was not time dependent, being fully established at 48 hours of exposure. Accordingly, in the clawed frog (Xenopus laevis) the lethal effects of carbendazim at 4-cell stage embryos proved to be higher than in embryos exposed later 
in the blastula stage as concluded by Yoon et al., (2008). Data reporting $\mathrm{LC}_{50}$ values of carbendazim to fish early life stages are scarce. The study of Rico et al. (2011) conducted with tambaqui (Colossoma macropomum) alevins reported a 96 h- $\mathrm{LC}_{50}$ of $4.16 \mathrm{mg} / \mathrm{L}$ (Rico et al., 2011), in the same range of the value found in this study (1.75 $\mathrm{mg} / \mathrm{L}$ ), while Palanikumar et al., (2014) reported a $96 \mathrm{~h}-\mathrm{LC}_{50}$ of $0.013 \mathrm{mg} / \mathrm{L}$ for fingerlings of milkfish (Chanos chanos). Ludwikowska et al., (2013) in a study with the prussian carp (Carassius gibelio) embryos only mention an effect of $100 \%$ mortality after $24 \mathrm{~h}$ of exposure to $0.216 \mathrm{mg} / \mathrm{L}$ of carbendazim.

Furthermore, carbendazim exposure strongly affected the development of embryos which is consistent with studies conducted in amphibian (Yoon et al., 2008) and rodent embryos (Farag et al., 2011) where the compound showed to be teratogenic increasing the incidence of malformations such as pericardial edemas, spinal lordosis, elongated heart, narrowed head among others. Similarly to our work, the body length of clawed frog (X. laevis) exposed to carbendazim was also decreased although effects were observed at lower concentrations ( $\geq 0.38 \mathrm{mg} / \mathrm{L}$ ) (Yoon et al., 2008). A previous study carried out with the parent compound of carbendazim (benomyl) in zebrafish embryos also showed decreased hatching and heart beat rate and increased incidence of malformations causing the same type of anomalies observed in our study in concentrations as low as $30 \mu \mathrm{g} / \mathrm{L}$ (Kim et al., 2009). Given that the half-life of benomyl is of only 180 minutes (pH 7.5) (Mallat et al, 1997) the mentioned effects can be mainly attributed to carbendazim, corroborating our results.

AChE plays an important role in neurotransmission being responsible for the hydrolysis of acetyltiocholine at the cholinergic synapses and neuromuscular junction (Olsen et al., 2001). In addition, there are evidences of the involvement of $\mathrm{AChE}$ in other physiological process including the regulation of cell proliferation and apoptosis as reviewed by Jiang \& Zhang (2008). A recent study conducted in zebrafish has demonstrated that embryonic exposure to carbendazim (4 to $500 \mu \mathrm{g} / \mathrm{L}$ ) led to significant changes in the expression of many genes with critical roles during cell apoptosis (Jiang et al., 2014). However, the mechanisms that regulate AChE expression and participation in apoptosis are not yet fully understood (Soreq and Seidman, 2001; Zhang et al., 2002). Considering that apoptosis is related to up regulation of acetylcholinesterase genes (Zhang et al., 2002), the increased ChE activity observed in our study is probably linked to carbendazim potential to induce cell apoptosis. Additionally, carbendazim, as an endocrine disruptor agent, is known to change the mRNA expression of thyroid related 
genes (among others) such as the thyroid hormone receptors (TR $\alpha$ and $T R \beta$ ), and iodothyronine deiodinases (Diol and Dio2) (Jiang et al. 2014). The involvement of thyroid hormones in the regulation of AChE activity has been suggested by several authors such as Puymirat et al. (1995). This regulation occurs via nuclear receptors that regulate the transcription of responsive genes and may also explain the differences in ChE activity obtained in this work.

GST represents a family of enzymes with a central role in the biotransformation of xenobiotics and endogenic compounds and their activity can be enhanced in response to xenobiotics. Thus, GST has been considered as an indicator of stress and increasingly used as an environmental biomarker (Hyne and Maher, 2003). In our work, GST activity was increased after exposure to carbendazim. Augmented activities were also observed following carbendazim and benomyl exposure in the midge Kiefferulus calligaster and in adult nile tilapia (Oreochromis niloticus) (Domingues et al., 2009; Min and Kang, 2008) respectively.

Similarly, LDH activity was induced in embryos exposed to carbendazim. LDH is a key enzyme in the anaerobic pathway of energy production and is involved in the carbohydrate metabolism (Diamantino et al., 2001). Increased LDH activity levels have been observed in conditions of chemical stress when high levels of energy are required as demonstrated in Nile tilapia exposed to benomyl (Min and Kang, 2008). It is possible that a metabolic hypoxia due to detoxification process increases the anaerobic pathways causing the LDH induction.

Jiang and co-authors (2015) observed a significant variation in the expression of genes related to antioxidant enzymes in zebrafish larvae after exposure to sublethal concentration of carbendazim, concluding that the compound might induce oxidative stress in zebrafish embryos. In our work CAT activity showed a trend to inhibit at low concentrations but this was not significant though.

In our study, the locomotor response of zebrafish embryos was very sensitive to carbendazim as observed by alterations in swimming activity of larvae even at the lowest tested concentration $(0.16 \mu \mathrm{g} / \mathrm{L})$. Organisms exposed to carbendazim, spent more time swimming, however the increment of time spent swimming was not translated in an increment of the distance moved (meaning that organisms swam slower). In the light periods, unexpectedly, the total distance moved even decreased, suggesting that fish were not able to swim at their regular speed. To our knowledge the only study available concerning carbendazim effects on fish behaviour is the recent study conducted in 
juveniles of the african sharptooth catfish (Claria gariepinus). Fish exposed to sublethal responses such as spiral swimming, hyperactivity, frequent surfacing to gulp water, erratic movement and loss of equilibrium (Nwani et al., 2015). Alteration of locomotor behaviour is very often linked with neurological impairment mediated by ChE inhibition, however this is not the case for carbendazim since this compound does not inhibit ChE as it is known from the literature (Kegley et al, 2014) and also confirmed in this work. Developmental malformations could also be responsible for locomotor impairment; however, concentrations used to assess locomotor effects in this study do not elicit any detectable developmental effects. On the other hand, behaviour alterations in fish may be the result of the integration of effects in several physiological systems such as the neurological, sensorial, hormonal, and metabolic (Scott and Sloman, 2004; Tierney, 2011); therefore multiple factors may be implied in the behaviour disruption detected for carbendazim. As explained above, the increased $\mathrm{ChE}$ activity may be the result of apoptosis and /or endocrine disruption. These processes are known to occur under carbendazim exposure (Jiang et al., 2015, 2014) and are also linked with behavioural disruption in several works (see Fredriksson et al., 2007; Pontén et al., 2012; Sharma et al., 2009 for apoptosis and Bell, 2001; Clotfelter et al., 2004; Sárria et al., 2011 for endocrine disruption. Moreover, behaviour effects, measured as swimming time, are also associated in the PCA to the GST and LDH which are general biomarkers of chemical and environmental stress. This suggests that the metabolic costs involved on detoxification processes may be compromising other important functions such as the locomotor response of zebrafish larvae. Results of a previous study in fish exposed to copper related the partitioning of energy utilization (between metabolism maintenance and locomotion) to altered fish behaviour (Handy et al., 1999), corroborating this hypothesis. Locomotor disruption observed in this work may thus, be the cumulative result of effects at several levels.

From an ecological point of view, the alterations in the swimming behaviour (which were observed at environmental relevant concentrations) can have important consequences for the fitness of the organisms as they can further originate feeding disruption (capability to capture prey) and increase vulnerability to predation (through an inability to remain inconspicuous) among other processes (Little and Finger, 1990). From Fig 5, which summarizes the "lowest observed effect concentrations- LOEC" of the several endpoints analysed in this work, one can easily observe that behavioural 
endpoints are several orders of magnitude more sensitive than developmental parameters and thus have the potential to work as an early warning signal for environmental stress. Further studies should focus on understanding how the behavioural disturbances measured translate into fitness impairment at the adult stage.

\section{Conclusion}

By acting on tubulin assembly which directly affects many cellular processes including mitosis, carbendazim is particularly pernicious to early life stages of development where active cell division is ongoing. This mechanism of action is reflected in several developmental anomalies here recorded in the range of 1 to $2 \mathrm{mg} / \mathrm{L}$ of carbendazim, such as pericardial edemas, body and tail deformities, decreased heart beat rate and body length. At the biochemical level, the increase in the ChE activity (in the range of 0.02 to $0.5 \mathrm{mg} / \mathrm{L}$ of carbendazim) is consistent with apoptosis, which in its turn can also be related to the embryo development anomalies above mentioned and to the behaviour (locomotor) disruption found. In addition, the increase in the ChE activity may also result from the endocrine disruption activity of carbendazim. The locomotor assay showed to be extremely sensitive, detecting effects at concentrations of $0.00016 \mathrm{mg} / \mathrm{L}$ (several orders of magnitude more sensitive that developmental parameters or lethality). These are ecological relevant concentrations and highlight the potential of behavioural endpoints as early warning signs for environmental stress. Since behavioural endpoints may translate in ecological relevant effects such as feeding behaviour of antipredatory behaviour disruption, these findings corroborate the importance of the emergent field of behavioural ecotoxicology as a relevant approach in ecological risk assessment strategies.

\section{Acknowledgements}

This study was supported by a PhD grant (SFRH/BD/74501/2010) attributed to Thayres Andrade and by the Post-Doc grant (SFRH/BPD/90521/2012) attributed to Inês Domingues by the Portuguese Science and Technology Foundation (FCT), funding by FEDER through COMPETE and Programa Operacional Factores de Competitividade and by National funding through FCT, within the research project Climatox-Impact of climatic changes on toxicity of pollutants (Ref. FCT PTDC/AAG-GLO/4059/2012).

\section{References}


Beauvais, S.L., Jones, S.B., Brewer, S.K., Little, E.E., 2000. Physiological measures of neurotoxicity of diazinon and malathion to larval rainbow trout (Oncorhynchus mykiss) and their correlation with behavioral measures. Environ. Toxicol. Chem. 19, 1875-1880.

Beauvais, S.L., Jones, S.B., Parris, J.T., Brewer, S.K., Little, E.E., 2001. Cholinergic and behavioral neurotoxicity of carbaryl and cadmium to larval rainbow trout (Oncorhynchus mykiss). Ecotoxicol. Environ. Saf. 49, 84-90. doi:10.1006/eesa.2000.2032

Bradford, M.M., 1976. A rapid and sensitive method for the quantitation of microgram quantities of protein utilizing the principle of protein-dye binding. Anal. Biochem. 72, 248-54.

Braunbeck, T., Kais, B., Lammer, E., Otte, J., Schneider, K., Stengel, D., Strecker, R., 2014. The fish embryo test (FET): origin, applications, and future. Environ. Sci. Pollut. Res. Int. doi:10.1007/s11356-014-3814-7

Clairborne, A., 1985. Catalase activity. In: RA, G. (Ed.), CRC handbook of methods in oxygen radical research. CRC Press, Boca Raton, FL, pp. 283-284.

Cuppen, J.G.M., Van den Brink, P.J., Camps, E., Uil, K.F., Brock, T.C.M., 2000a. Impact of the fungicide carbendazim in freshwater microcosms. I. Water quality, breakdown of particulate organic matter and responses of macroinvertebrates. Aquat. Toxicol. 48, 233250. doi:10.1016/S0166-445X(99)00036-3

Cuppen, J.G.M., Van den Brink, P.J., Camps, E., Uil, K.F., Brock, T.C.M., 2000b. Impact of the fungicide carbendazim in freshwater microcosms. I. Water quality, breakdown of particulate organic matter and responses of macroinvertebrates. Aquat. Toxicol. 48, 233250. doi:10.1016/S0166-445X(99)00036-3

Daam, M.A., Satapornvanit, K., Van den Brink, P.J., Nogueira, A.J.A., 2010. Direct and indirect effects of the fungicide Carbendazim in tropical freshwater microcosms. Arch. Environ. Contam. Toxicol. 58, 315-24. doi:10.1007/s00244-009-9367-y

Davidse, L.C., 1986. Benzimidazole Fungicides: Mechanism of Action and Biological Impact. Annu. Rev. Phytopathol. 24, 43-65. doi:10.1146/annurev.py.24.090186.000355

Domingues, I., Guilhermino, L., Soares, A.M.V.M., Nogueira, A.J.A., Monaghan, K.A., 2009. Influence of exposure scenario on pesticide toxicity in the midge Kiefferulus calligaster (Kieffer). Ecotoxicol. Environ. Saf. 72, 450-7. doi:10.1016/j.ecoenv.2007.10.009

Domingues, I., Oliveira, R., Lourenço, J., Grisolia, C.K., Mendo, S., Soares, a M.V.M., 2010. Biomarkers as a tool to assess effects of chromium (VI): comparison of responses in zebrafish early life stages and adults. Comp. Biochem. Physiol. C. Toxicol. Pharmacol. 152, 338-45. doi:10.1016/j.cbpc.2010.05.010

Ellman, G.L., Courtney, K.D., Andres Jr., V., Featherstone, R.M., 1961. A new rapid colorimetric determination of acetylcholinesterase activity. Biochem. Pharmacol. 7, 8895.

Farag, A., Ebrahim, H., ElMazoudy, R., Kadous, E., 2011. Developmental toxicity of fungicide carbendazim in female mice. Birth Defects Res. B. Dev. Reprod. Toxicol. 92, 122-30. doi:10.1002/bdrb.20290

Ferreira, A.L.G., Loureiro, S., Soares, A.M.V.M., 2008. Toxicity prediction of binary combinations of cadmium, carbendazim and low dissolved oxygen on Daphnia magna. Aquat. Toxicol. 89, 28-39. doi:10.1016/j.aquatox.2008.05.012

Fredriksson, A., Pontén, E., Gordh, T., Eriksson, P., 2007. Neonatal exposure to a combination of N-methyl-D-aspartate and gamma-aminobutyric acid type A receptor anesthetic agents potentiates apoptotic neurodegeneration and persistent behavioral deficits. Anesthesiology 107, 427-36. doi:10.1097/01.anes.0000278892.62305.9c 
Habig, W.H., Jakoby, W.B., 1981. Assays for differentiation of glutathione S-transferases. Methods Enzymol. 77, 398-405.

Handy, R., Sims, D.., Giles, A., Campbell, H.., Musonda, M.., 1999. Metabolic trade-off between locomotion and detoxification for maintenance of blood chemistry and growth parameters by rainbow trout (Oncorhynchus mykiss) during chronic dietary exposure to copper. Aquat. Toxicol. 47, 23-41. doi:10.1016/S0166-445X(99)00004-1

Hyne, R. V, Maher, W.A., 2003. Invertebrate biomarkers: links to toxicosis that predict population decline. Ecotoxicol. Environ. Saf. 54, 366-374. doi:10.1016/S01476513(02)00119-7

Ireland, C., Gull, K., Gutteridge, W., Pogson, C., 1979. The interaction of benzimidazole carbamates with mammalian microtobule protein. Biochem. Pharmacol.

Irons, T.D., MacPhail, R.C., Hunter, D.L., Padilla, S., 2010. Acute neuroactive drug exposures alter locomotor activity in larval zebrafish. Neurotoxicol. Teratol. 32, 84-90. doi:http://dx.doi.org/10.1016/j.ntt.2009.04.066

Jiang, H., Zhang, X.-J., 2008. Acetylcholinesterase and apoptosis. A novel perspective for an old enzyme. FEBS J. 275, 612-7. doi:10.1111/j.1742-4658.2007.06236.x

Jiang, J., Wu, S., Wu, C., An, X., Cai, L., Zhao, X., 2014. Embryonic exposure to carbendazim induces the transcription of genes related to apoptosis, immunotoxicity and endocrine disruption in zebrafish (Danio rerio). Fish Shellfish Immunol. 41, 493-500. doi:10.1016/j.fsi.2014.09.037

Jiang, J., Wu, S., Wang, Y., An, X., Cai, L., Zhao, X., Wu, C., 2015. Carbendazim has the potential to induce oxidative stress, apoptosis, immunotoxicity and endocrine disruption during zebrafish larvae development. Toxicol. In Vitro 29, 1473-81. doi:10.1016/j.tiv.2015.06.003

Kim, D.-J., Seok, S.-H., Baek, M.-W., Lee, H.-Y., Na, Y.-R., Park, S.-H., Lee, H.-K., Dutta, N.K., Kawakami, K., Park, J.-H., 2009. Benomyl induction of brain aromatase and toxic effects in the zebrafish embryo. J. Appl. Toxicol. 29, 289-94. doi:10.1002/jat.1405

Kimmel, C.B., Ballard, W.W., Kimmel, S.R., Ullmann, B., Schilling, T.F., 1995. Stages of embryonic development of the zebrafish. Dev. Dyn. 203, 253-310. doi:10.1002/aja.1002030302

Kegley, S.E., Hill, B.R., Orme S., Choi A.H., PAN Pesticide Database, Pesticide Action Network, North America (Oakland, CA, 2014), http:www.pesticideinfo.org (accessed $10 / 11 / 2015)$

Klüver, N., König, M., Ortmann, J., Massei, R., Paschke, A., Kühne, R., Scholz, S., 2015. Fish Embryo Toxicity Test: Identification of Compounds with Weak Toxicity and Analysis of Behavioral Effects To Improve Prediction of Acute Toxicity for Neurotoxic Compounds. Environ. Sci. Technol. 49, 7002-11. doi:10.1021/acs.est.5b01910

Lim, J., Miller, M.G., 1997. The role of the benomyl metabolite carbendazim in benomylinduced testicular toxicity. Toxicol. Appl. Pharmacol. 142, 401-10. doi:10.1006/taap.1996.8042

Little, E.E., Finger, S.E., 1990. Swimming behavior as an indicator of sublethal toxicity in fish. Environ. Toxicol. Chem. 9, 13-19. doi:10.1002/etc.5620090103

Ludwikowska, A., Bojarski, B., Socha, M., Lutnicka, H., Trzeciak, K.B., 2013. The effect of carbendazim on embryonic Prussian carp ( Carassius gibelio ) development and hatching 367-371. doi:10.2478/aopf-2013-0038

Mallat, E., Barceló, D., Tauler, R., 1997. Degradation study of benomyl and carbendazim in water by liquid chromatography and multivariate curve resolution methods. Chromatographia 46, 342-350. doi:10.1007/BF02490871 
Min, E.Y., Kang, J.-C., 2008. Effect of waterborne benomyl on the hematological and antioxidant parameters of the Nile tilapia, Oreochromis niloticus. Pestic. Biochem. Physiol. 92, 138-143. doi:10.1016/j.pestbp.2008.07.007

Nagel, R., 2002. DarT: The embryo test with the Zebrafish Danio rerio--a general model in ecotoxicology and toxicology. ALTEX Altern. zu Tierexperimenten.

Nakai, M., Miller, M., Carnes, K., Hess, R.., 2002. Stage-specific effects of the fungicide carbendazim on Sertoli cell microtubules in rat testis. Tissue Cell 34, 73-80. doi:10.1016/S0040-8166(02)00006-X

Nwani, C., Omah, M., Ivoke, N., Nwamba, H., Ani, C., Ogbonna, S., 2015. Biochemical, haematological and morphological variations in juvenile Clarias gariepinus exposed to Carbendazim ${ }^{\circledR}$ fungicide. African J. Aquat. Sci. 40, 63-71. doi: $10.2989 / 16085914.2015 .1014022$

OECD, 2013. Test No. 236: Fish Embryo Acute Toxicity (FET) Test, OECD Guidelines for the Testing of Chemicals, Section 2, OECD Publishing. doi:10.1787/9789264203709-en

Oliveira, R., Domingues, I., Koppe Grisolia, C., Soares, A.M.V.M., 2009. Effects of triclosan on zebrafish early-life stages and adults. Environ. Sci. Pollut. Res. Int. 16, 679-688. doi:10.1007/s11356-009-0119-3

Olsen, T., Ellerbeck, L., Fisher, T., Callaghan, A., Crane, M., 2001. Variability in acetylcholinesterase and glutathione S-transferase activities in Chironomus riparius Meigen deployed in situ at uncontaminated field sites. Environ. Toxicol. Chem. 20, 172532.

Padilla, S., Hunter, D.L., Padnos, B., Frady, S., MacPhail, R.C., 2011. Assessing locomotor activity in larval zebrafish: Influence of extrinsic and intrinsic variables. Neurotoxicol. Teratol. 33, 624-630. doi:10.1016/j.ntt.2011.08.005

Palanikumar, L., Kumaraguru, a. K., Ramakritinan, C.M., Anand, M., 2014. Toxicity, biochemical and clastogenic response of chlorpyrifos and carbendazim in milkfish Chanos chanos. Int. J. Environ. Sci. Technol. 11, 765-774. doi:10.1007/s13762-013-0264-6

Palma, G., Sánchez, A., Olave, Y., Encina, F., Palma, R., Barra, R., 2004. Pesticide levels in surface waters in an agricultural-forestry basin in Southern Chile. Chemosphere 57, 76370. doi:10.1016/j.chemosphere.2004.08.047

Pontén, E., Viberg, H., Gordh, T., Eriksson, P., Fredriksson, A., 2012. Clonidine abolishes the adverse effects on apoptosis and behaviour after neonatal ketamine exposure in mice. Acta Anaesthesiol. Scand. 56, 1058-65. doi:10.1111/j.1399-6576.2012.02722.x

Puymirat, J., Etongue-Mayer, P., Dussault, J.H., 1995. Thyroid Hormones Stabilize Acetylcholinesterase mRNA in Neuro-2A Cells That Overexpress the $\beta 1$ Thyroid receptor. J. Biol. Chem. 270 (51), 30651-30656.

R Core Team, 2014. R: a language and environment for statistical computing. R Foundation for Statistical Computing, Vienna, Austria.

Readman, J.W., Albanis, T.A., Barcelo, D., Galassi, S., Tronczynski, J., Gabrielides, G.P., 1997. Fungicide contamination of Mediterranean estuarine waters: Results from a MED POL pilot survey. Mar. Pollut. Bull. 34, 259-263. doi:10.1016/S0025-326X(97)00101-X

Ribeiro, F., Ferreira, N.C.G., Ferreira, A., Soares, A.M.V.M., Loureiro, S., 2011. Is ultraviolet radiation a synergistic stressor in combined exposures? The case study of Daphnia magna exposure to UV and carbendazim. Aquat. Toxicol. 102, 114-22. doi:10.1016/j.aquatox.2011.01.007

Rico, A., Waichman, A. V., Geber-Corrêa, R., Van Den Brink, P.J., 2011. Effects of malathion and carbendazim on Amazonian freshwater organisms: Comparison of tropical and 
temperate species sensitivity distributions. Ecotoxicology 20, 625-634. doi:10.1007/s10646-011-0601-9

Scholz, S., Fischer, S., Gündel, U., Küster, E., Luckenbach, T., Voelker, D., 2008. The zebrafish embryo model in environmental risk assessment--applications beyond acute toxicity testing. Environ. Sci. Pollut. Res. Int. 15, 394-404. doi:10.1007/s11356-008-0018-z

Scholz, S., Sela, E., Blaha, L., Braunbeck, T., Galay-Burgos, M., García-Franco, M., Guinea, J., Klüver, N., Schirmer, K., Tanneberger, K., Tobor-Kapłon, M., Witters, H., Belanger, S., Benfenati, E., Creton, S., Cronin, M.T.D., Eggen, R.I.L., Embry, M., Ekman, D., Gourmelon, A., Halder, M., Hardy, B., Hartung, T., Hubesch, B., Jungmann, D., Lampi, M.A., Lee, L., Léonard, M., Küster, E., Lillicrap, A., Luckenbach, T., Murk, A.J., Navas, J.M., Peijnenburg, W., Repetto, G., Salinas, E., Schüürmann, G., Spielmann, H., Tollefsen, K.E., Walter-Rohde, S., Whale, G., Wheeler, J.R., Winter, M.J., 2013. A European perspective on alternatives to animal testing for environmental hazard identification and risk assessment. Regul. Toxicol. Pharmacol. 67, 506-30. doi:10.1016/j.yrtph.2013.10.003

Scott, G.R., Sloman, K.A., 2004. The effects of environmental pollutants on complex fish behaviour: integrating behavioural and physiological indicators of toxicity. Aquat. Toxicol. 68, 369-92. doi:10.1016/j.aquatox.2004.03.016

Selderslaghs, I.W.T., Hooyberghs, J., De Coen, W., Witters, H.E., 2010. Locomotor activity in zebrafish embryos: a new method to assess developmental neurotoxicity. Neurotoxicol. Teratol. 32, 460-471. doi:10.1016/j.ntt.2010.03.002

Selmanoğlu, G.Barlas, N.Songür, S.Koçkaya, E.A., 2001. Carbendazim-induced haematological, biochemical and histopathological changes to the liver and kidney of male rats. Hum. Exp. Toxicol. 20, 625-630.

Sharma, D.R., Sunkaria, A., Bal, A., Bhutia, Y.D., Vijayaraghavan, R., Flora, S.J.S., Gill, K.D., 2009. Neurobehavioral impairments, generation of oxidative stress and release of proapoptotic factors after chronic exposure to sulphur mustard in mouse brain. Toxicol. Appl. Pharmacol. 240, 208-18. doi:10.1016/j.taap.2009.06.015

Soreq, H., Seidman, S., 2001. Acetylcholinesterase--new roles for an old actor. Nat. Rev. Neurosci. 2, 294-302. doi:10.1038/35067589

Tierney, K.B., 2011. Behavioural assessments of neurotoxic effects and neurodegeneration in zebrafish. Biochim. Biophys. Acta - Mol. Basis Dis. 1812, 381-389. doi:10.1016/j.bbadis.2010.10.011

Ulhaq, M., Örn, S., Carlsson, G., Morrison, D. a., Norrgren, L., 2013. Locomotor behavior in zebrafish (Danio rerio) larvae exposed to perfluoroalkyl acids. Aquat. Toxicol. 144-145, 332-340. doi:10.1016/j.aquatox.2013.10.021

Urani, C., Chiesara, E., Galvani, P., Marabini, L., Santagostino, A., Camatini, M., 1995. Benomyl affects the microtubule cytoskeleton and the glutathione level of mammalian primary cultured hepatocytes. Toxicol. Lett. 76, 135-44.

Van den Brink, P.J., Hattink, J., Bransen, F., Van Donk, E., Brock, T.C.M., 2000. Impact of the fungicide carbendazim in freshwater microcosms. II. Zooplankton, primary producers and final conclusions. Aquat. Toxicol. 48, 251-264. doi:10.1016/S0166-445X(99)00037-5

Vassault, A., 1983. Lactate dehydrogenase, in: Academic Press. New York.

Yoon, C.-S., Jin, J.-H., Park, J.-H., Yeo, C.-Y., Kim, S.-J., Hwang, Y.-G., Hong, S.-J., Cheong, S.-W., 2008. Toxic effects of carbendazim and n-butyl isocyanate, metabolites of the fungicide benomyl, on early development in the African clawed frog, Xenopus laevis. Environ. Toxicol. 23, 131-44. doi:10.1002/tox.20338 
Zhang, X.J., Yang, L., Zhao, Q., Caen, J.P., He, H.Y., Jin, Q.H., Guo, L.H., Alemany, M., Zhang, L.Y., Shi, Y.F., 2002. Induction of acetylcholinesterase expression during apoptosis in various cell types. Cell Death Differ. 9, 790-800. doi:10.1038/sj.cdd.4401034 
Table 1 - Effects of carbendazim on the developmental parameters of zebrafish embryos. $\mathrm{L}(\mathrm{E}) \mathrm{C}$ values are presented in $\mathrm{mg} / \mathrm{L}$ and are followed by the standard error.

\begin{tabular}{|c|c|c|c|c|c|c|c|c|}
\hline \multirow{2}{*}{$\begin{array}{c}\text { Developmental } \\
\text { parameters }\end{array}$} & \multicolumn{2}{|c|}{24 hpf } & \multicolumn{2}{|c|}{48 hpf } & \multicolumn{2}{|c|}{72 hpf } & \multicolumn{2}{|c|}{$96 \mathrm{hpf}$} \\
\hline & $L(E) C_{10}$ & $L(E) C_{50}$ & $L(E) C_{10}$ & $L(E) C_{50}$ & $L(E) C_{10}$ & $L(E) C_{50}$ & $L(E) C_{10}$ & $\mathbf{L}(\mathbf{E}) \mathbf{C}_{50}$ \\
\hline Somite formation & n.e. & n.e. & - & - & - & - & - & - \\
\hline General deformities & $1.27 \pm 0.03$ & $1.48 \pm 0.03$ & - & - & - & - & - & - \\
\hline Heartbeat & - & - & $1.18 \pm 0.12$ & $1.86 \pm 0.05$ & - & - & - & - \\
\hline $\begin{array}{l}\text { Developmental } \\
\text { delay }\end{array}$ & n.e. & n.e. & $1.56 \pm 0.11$ & $1.59 \pm 0.08$ & n.e. & n.e. & n.e. & n.e. \\
\hline $\begin{array}{l}\text { Head and eye } \\
\text { deformity }\end{array}$ & n.e. & n.e & $1.55 \pm 0.07$ & $1.60 \pm 0.043$ & $1.39 \pm 0.02$ & $1.52 \pm 0.01$ & $1.41 \pm 0.03$ & $1.53 \pm 0.02$ \\
\hline Tail deformity & n.e. & n.e. & n.e. & n.e. & $1.44 \pm 0.02$ & $1.52 \pm 0.01$ & $1.38 \pm 0.03$ & $1.54 \pm 0.02$ \\
\hline Spine deformity & n.e & n.e. & $1.42 \pm 0.05$ & $1.53 \pm 0.02$ & $1.33 \pm 0.02$ & $1.46 \pm 0.02$ & $1.31 \pm 0.02$ & $1.46 \pm 0.01$ \\
\hline Edema & n.d. & n.d. & $0.88 \pm 0.08$ & $1.26 \pm 0.08$ & $0.85 \pm 0.07$ & $1.24 \pm 0.06$ & $0.89 \pm 0.04$ & $1.08 \pm 0.02$ \\
\hline Hatching rate & - & - & - & - & $1.50 \pm 0.04$ & $1.57 \pm 0.04$ & $1.54 \pm 0.03$ & $1.62 \pm 0.01$ \\
\hline Body length & - & - & - & - & - & - & $1.42 \pm 0.02$ & $1.72 \pm 0.04$ \\
\hline Yolk sac length & - & - & - & - & - & - & $1.33 \pm 0.09$ & $1.35 \pm 0.09$ \\
\hline Survival & n.d. & n.d. & $1.70 \pm 0.11$ & $1.75 \pm 0.18$ & $1.63 \pm 0.06$ & $1.74 \pm 0.61$ & $1.48 \pm 0.05$ & $1.76 \pm 0.13$ \\
\hline
\end{tabular}




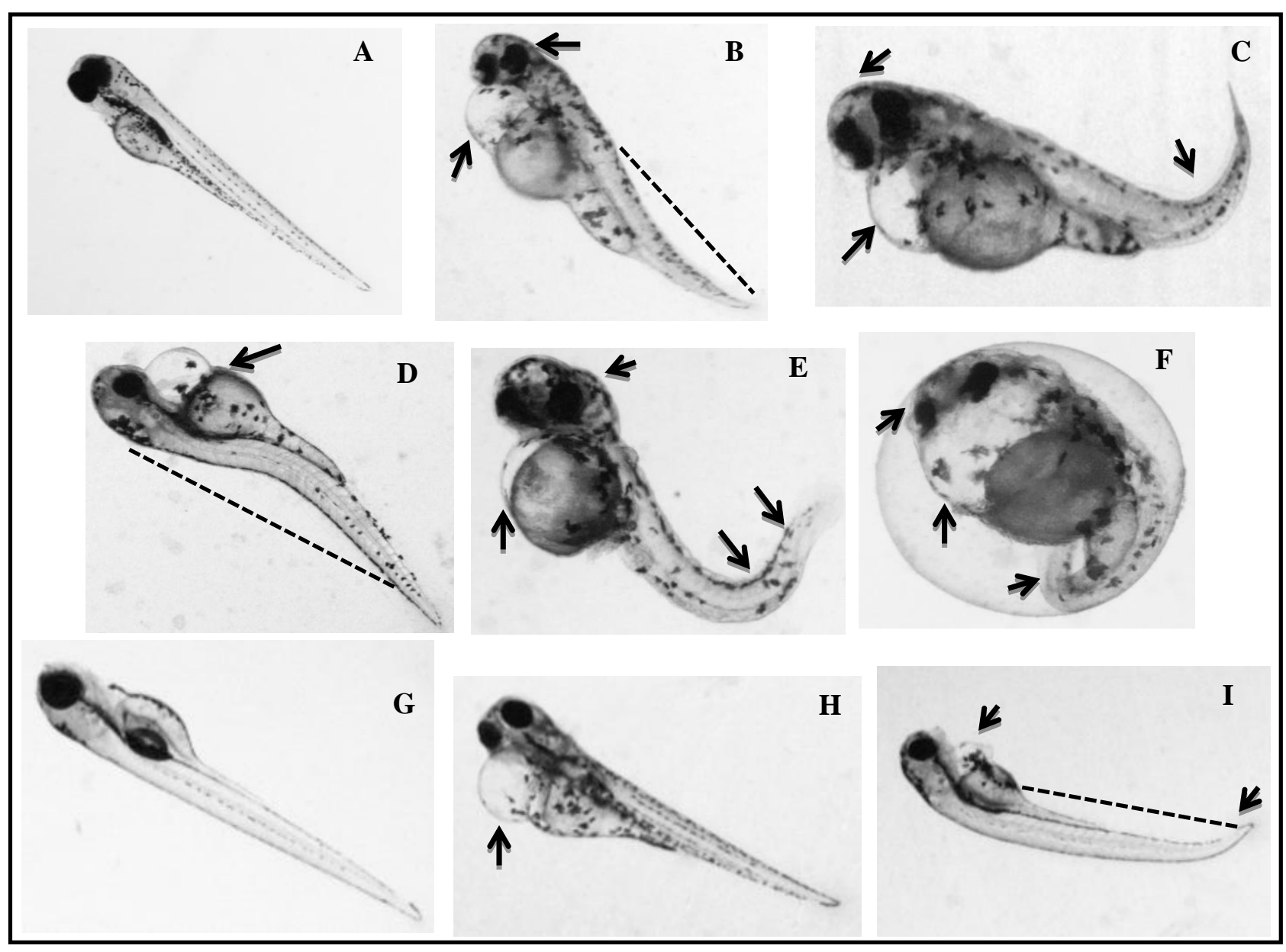

Fig 1 - Zebrafish embryos abnormalities during exposure to carbendazim. A) Control embryo at $72 \mathrm{~h}$ of exposure; B) Embryo (72 h) exposed to $1.41 \mathrm{mg} / \mathrm{L}$ showing pericardial edema, head and spine deformities; $\mathrm{C}, \mathrm{D}$ and E) Embryos exposed to $1.53 \mathrm{mg} / \mathrm{L}$ of carbendazim after $72 \mathrm{~h}$ of exposure presenting pericardial edema, eye, head and spine with severe deformities; F) unhatched embryo (72 h) exposed to $1.66 \mathrm{mg} / \mathrm{L}$ presenting a severe pericardial edema, head, eye and tail deformities; G) Control embryo at $96 \mathrm{~h} ; \mathrm{H}$ ) Embryo (96 h) exposed to $1.19 \mathrm{mg} / \mathrm{L}$ presenting pericardial edema and I) Embryo (96 h) exposed to 1.3 $\mathrm{mg} / \mathrm{L}$ presenting pericardial edema and spine deformity. 

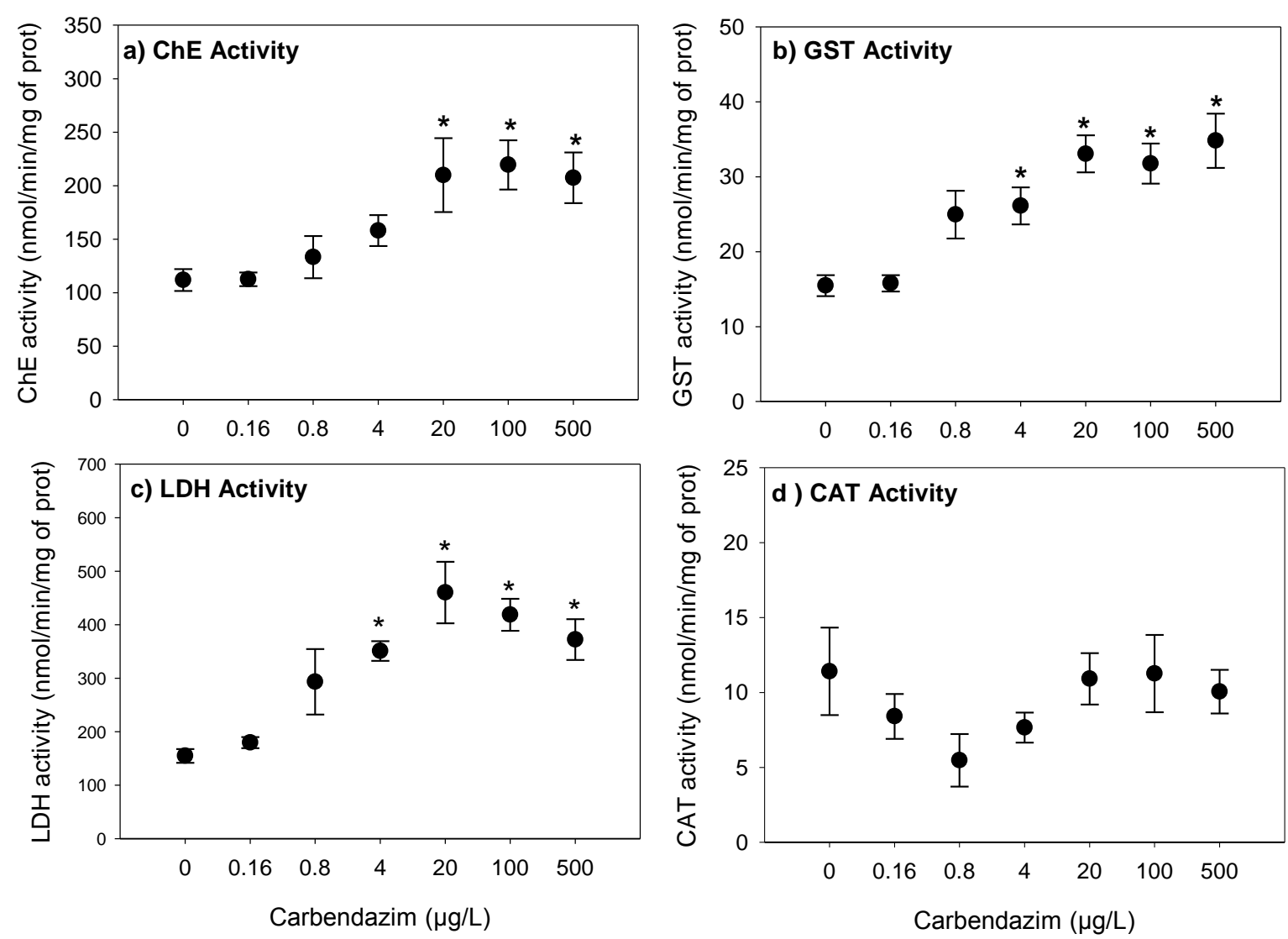

Fig. 2 - Enzymatic activities (mean values \pm standard error) of zebrafish embryos after 96 hours of exposure to carbendazim: a) ChE activity; b) GST activity; c) LDH activity and d) CAT activity. Asterisks mean significantly different from the respective control $(\mathrm{p}<0.05)$. 

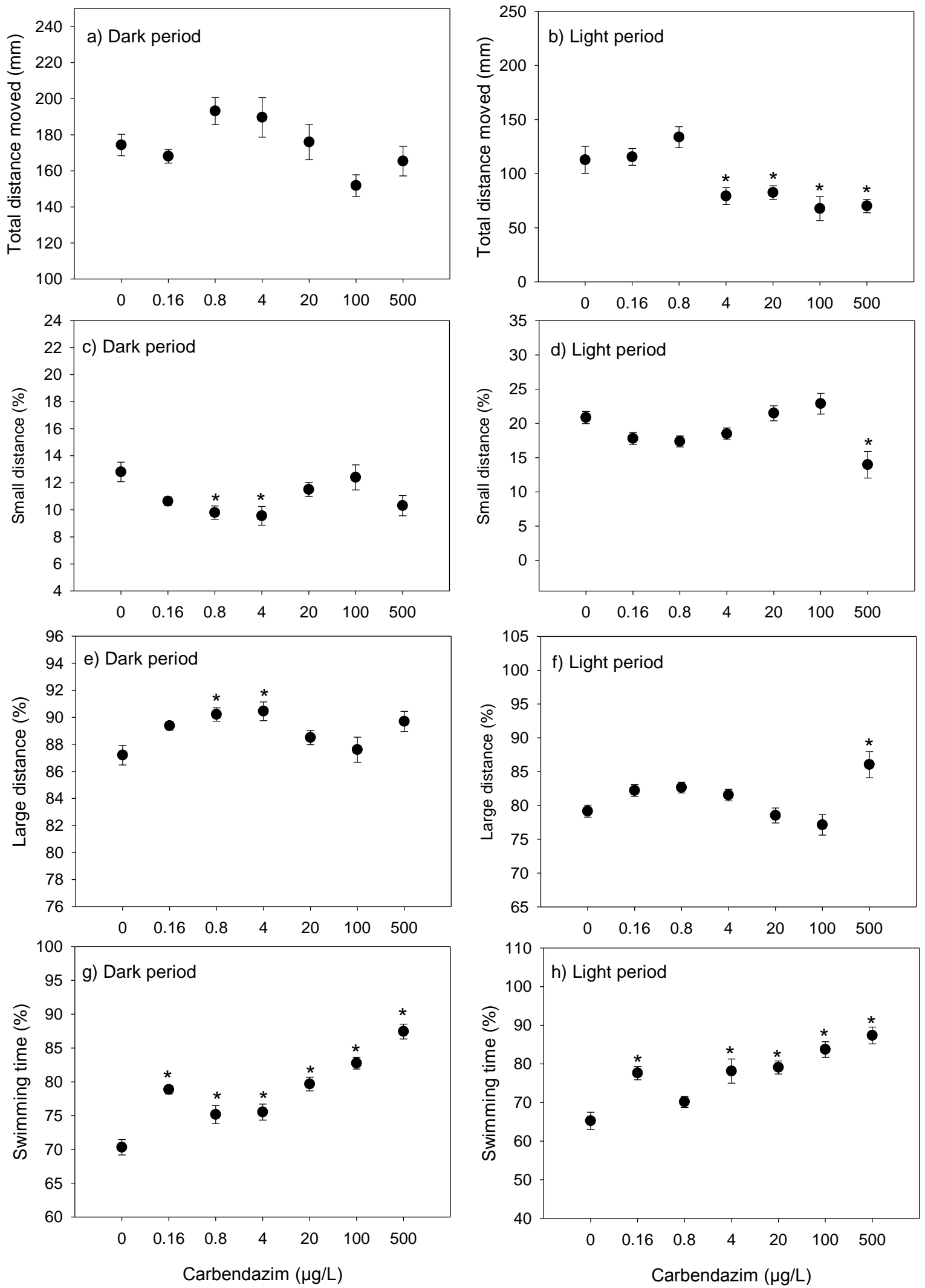

Fig. 3 - Effects of carbendazim on embryos locomotion in the first dark and light period: a) and b) represent the total distance moved by larvae; c) and d) refers to the small distance in relation to the total 
distance moved; e) and f) represent the large distance in relation to total distance moved and g) and h) refers to the time larvae spent moving in relation to the total time. Values are mean values \pm standard error and asterisks indicate significantly different from control $(\mathrm{p}<0.05)$.
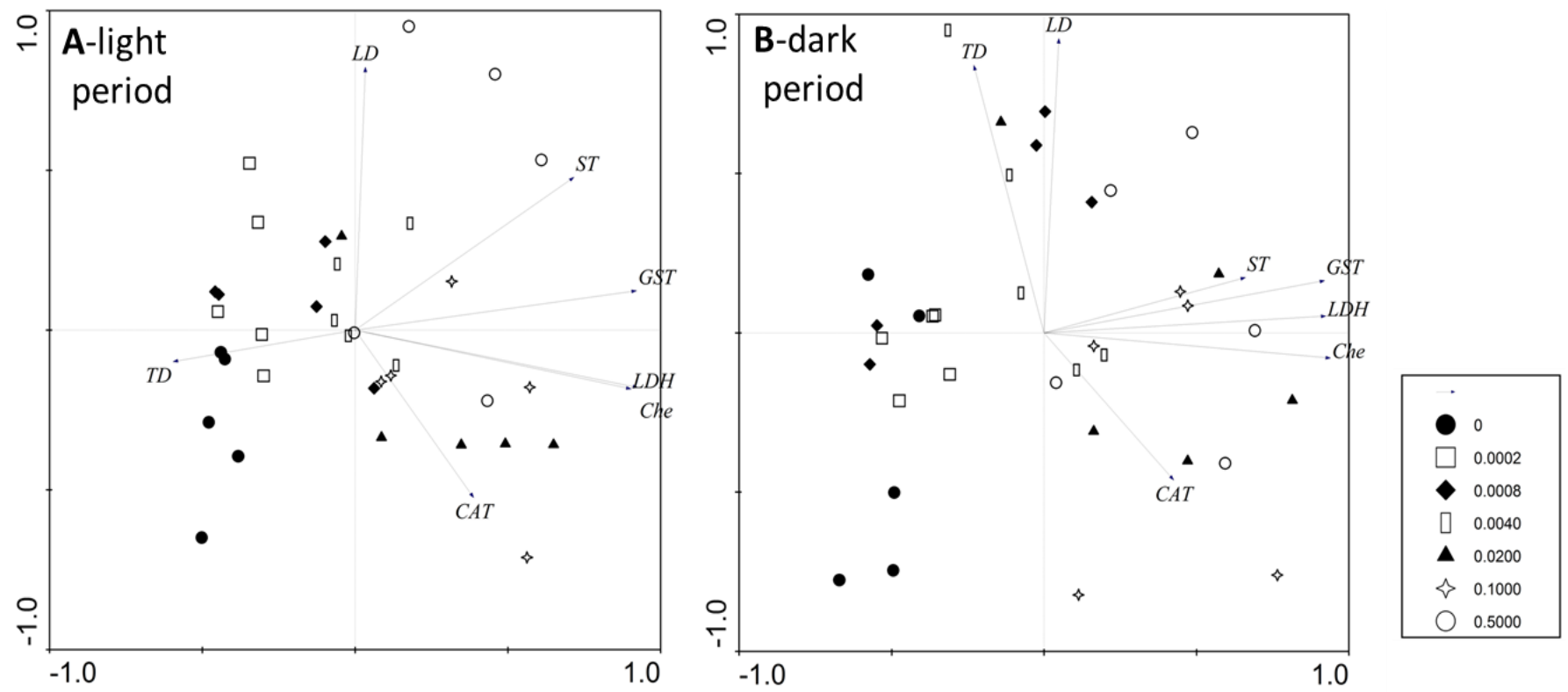

Fig. 4 - Biplot of the Principal Components Analysis (PCA) performed on different concentrations of carbendazim (symbols). The ordination was made in relation to behaviour endpoints TD (Total distance), LD (Large distance) and ST (Swimming time) and biochemical (GST, LDH, ChE, CAT) response variables (arrows).

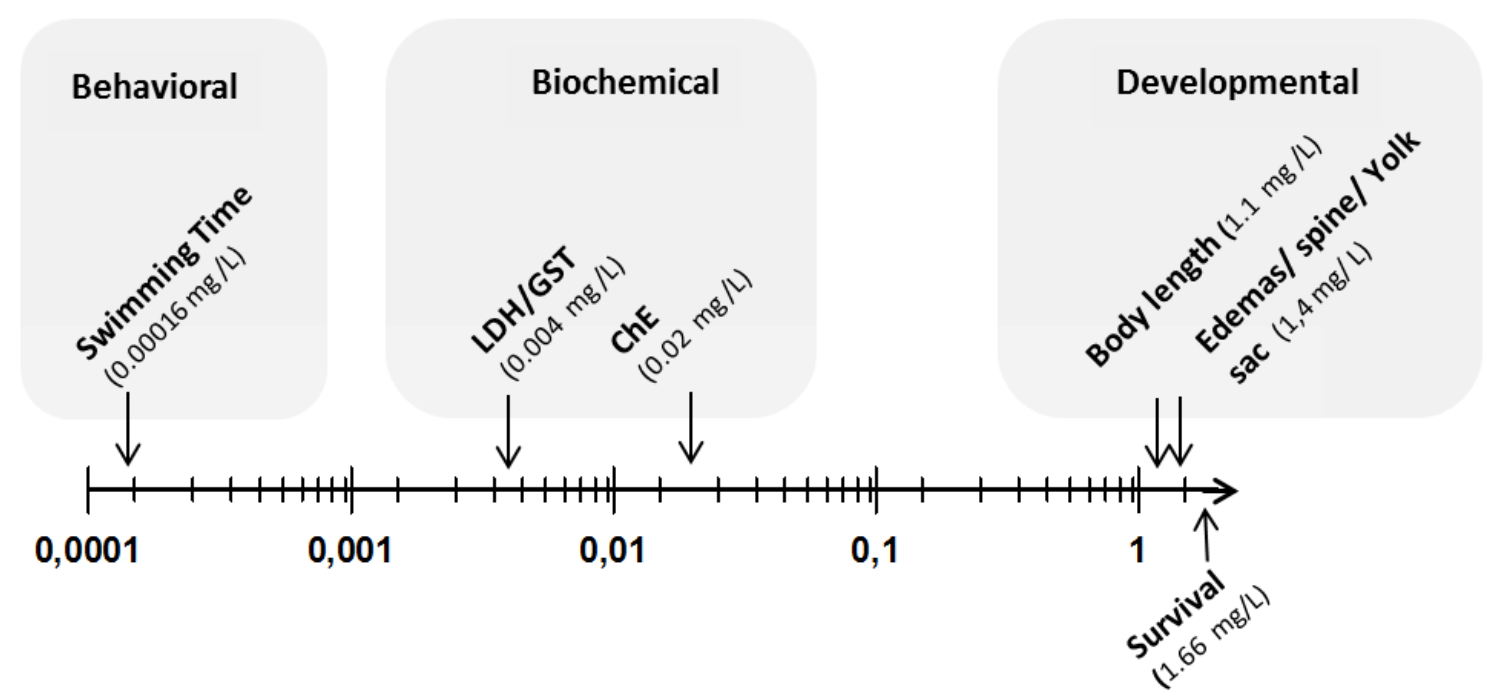


Fig. 5- Diagram comparing the relative sensitivity of endpoints used in the present work to assess effects of carbendazim in Danio rerio embryos. Values between brackets are Lowest Observed Effect Concentrations (LOEC). 